\title{
OS IMPACTOS DA DESONERAÇÃO DA FOLHA DE PAGAMENTOS EM UMA EMPRESA DE TECNOLOGIA DA INFORMAÇÃO
}

\author{
THE IMPACTS OF THE "PAYROLL TAX RELIEF" TO AN INFORMATION \\ TECHNOLOGY COMPANY
}

\begin{abstract}
TAIANA BEATRIZ JUNKES DA SILVEIRA
Graduada em Administração Pública pela Universidade do Estado de Santa Catarina e Graduada em Ciências Contábeis pela Universidade Federal de Santa Catarina. Endereço: Universidade do Estado de Santa Catarina, Escola Superior de Administração e Gerência. Av. Madre Benvenuta, 2.037 | Itacorubi | 88035-001 / Florianópolis/SC | Brasil.

E-mail: taiana16@hotmail.com
\end{abstract}

\section{FABIANO MAURY RAUPP}

Doutor, Universidade do Estado de Santa Catarina. Endereço: Universidade do Estado de Santa Catarina, Escola Superior de Administração e Gerência. Av. Madre Benvenuta, 2.037 / Itacorubi / 88035-001 | Florianópolis/SC / Brasil.

E-mail: fabianoraupp@hotmail.com

\section{RESUMO}

Em 2011 foi instituído o Plano Brasil Maior com o intuito de acelerar o crescimento do investimento produtivo, o esforço tecnológico, a inovação das empresas nacionais e aumentar a competitividade dos bens e serviços nacionais. Dentre as medidas instituídas por esse plano está a substituição, para alguns setores da economia, da Contribuição Previdenciária Patronal (CPP) pela Contribuição Previdenciária sobre a Receita Bruta (CPRB), ou "desoneração da folha de pagamentos". Nesse sentido, o objetivo desta pesquisa consistiu em investigar o impacto da "desoneração da folha de pagamentos" sobre os gastos com encargos trabalhistas incorridos por uma empresa de tecnologia da informação localizada em Florianópolis. Foi realizada uma pesquisa exploratória, por meio de um estudo de caso, com abordagem qualiquantitativa. Os resultados indicam que a partir da implementação da desoneração da folha de pagamentos a empresa obteve uma economia nos gastos com contribuição previdenciária. Além disso, constatou-se que, a partir do período em que a empresa pôde optar pelo recolhimento de uma ou outra contribuição previdenciária (CPP ou CPRB), foi mais interessante fazer a escolha pela Contribuição previdenciária sobre a Receita Bruta.

Palavras-chave: Desoneração da folha de pagamento. Contribuição Previdenciária Patronal. Contribuição Previdenciária sobre a Receita Bruta. 


\begin{abstract}
In order to accelerate the growth of productive investment, the technological effort and the innovation in domestic companies, as well as the increase the competitiveness of national goods and services, the program "Brasil Maior" was established, in 2011. One of the measures imposed by this plan is the replacement, for some sectors of the economy, of Social Security Employer tax (taxes on labor) to Social Security tax on revenue, or "Payroll tax relief". In this sense, the objective of this paper is to investigate the impact of this substitution on labor charges expenditures incurred by an Information Technology company located in Florianópolis. An exploratory research was carried out through a case study with qualitative and quantitative approaches. The results indicate that after the implementation of the Social Security tax on revenue, the company achieved savings in social security tax expenditures. Finally, it was found that as of the period when the company could opt for the payment of one or another social security contribution, it has been more interesting to opt for the social security contribution on total revenue.
\end{abstract}

Keywords: Payroll tax relief. Social Security Employer tax. Social Security tax on revenue.

\title{
1 INTRODUÇÃO
}

Com o slogan "Inovar para competir. Competir para crescer", foi instituído em 2011 o Plano Brasil Maior, que tem como objetivo acelerar o crescimento do investimento produtivo, o esforço tecnológico, a inovação das empresas nacionais, e aumentar a competitividade dos bens e serviços nacionais (Plano Brasil Maior, 2011).

De acordo com o disposto na Cartilha Brasil Maior, "o Plano Brasil Maior integra instrumentos de vários ministérios e órgãos do Governo Federal cujas iniciativas e programas se somam num esforço integrado e abrangente de geração de emprego e renda em benefício do povo brasileiro". Dentre as medidas instituídas pelo Plano Brasil Maior está a substituição da Contribuição Previdenciária Patronal (CPP) pela Contribuição Previdenciária sobre a Receita Bruta (CPRB), ou "desoneração da folha de pagamentos", para alguns setores da economia. A CPRB foi instituída pela Medida Provisória $\mathrm{n}^{\circ} 540$ de 02 de agosto de 2011, que posteriormente foi convertida na Lei $n^{\circ} 12.546$ de 14 de dezembro de 2011.

Dentre outras regras, essa medida provisória instituiu a substituição da CPP, cuja incidência consiste na aplicação da alíquota de $20 \%$ sobre a folha de pagamentos, pela CPRB, que consiste em incidir a uma alíquota determinada pela legislação, sobre a receita bruta auferida pelas empresas. A medida não contemplou todos os setores da economia, restringindo-se inicialmente a alguns, dentre eles as empresas de Tecnologia da Informação (TI) e Tecnologia da Informação e Comunicação (TIC), que, segundo Dallava (2014), foram os setores mais beneficiados com a desoneração da folha de pagamentos em 2012, em termos de renúncia fiscal.

Além disso, em 2012, esses setores apresentaram maior variação positiva na quantidade de funcionários em relação a 2011 (Dallava, 2014). Com a nova regra, os setores de empresas definidos pela legislação estavam obrigados a recolher essa contribuição substitutiva, independentemente de serem desonerados ou não com a medida. Desde a instituição da desoneração da folha de pagamentos houve diversas alterações na legislação, que, além de incluir novos setores, modificaram as alíquotas incidentes sobre a receita bruta. A mais recente alteração, que passou a vigorar a partir de $1^{\circ}$ de dezembro de 2015 , além do aumento das alíquotas, permitiu que as empresas optassem pelo recolhimento de uma ou outra contribuição, ou seja, a CPP ou a CPRB. Portanto, não estarão mais obrigadas a recolher a Contribuição Previdenciária sobre a receita bruta, desde que voltem a recolher os $20 \%$ sobre a folha de pagamentos.

Considerando o exposto, empreendeu-se estudo de caso sobre o impacto da "desoneração da folha de pagamentos" nos gastos com encargos trabalhistas incorridos por uma empresa de tecnologia da informação localizada em Florianópolis. Com base nas informações disponibilizadas pela empresa, relativas à receita bruta e às folhas de pagamentos realizadas no período que compreende 2011 a 2016, comparando-se os gastos da empresa 
com contribuição previdenciária a partir de três períodos: o período em que a contribuição previdenciária deveria ser recolhida sobre a folha de pagamentos (até novembro de 2011); o período em que passou a ser obrigatório o recolhimento sobre a receita bruta (dezembro de 2011 até novembro de 2015); e o início do período em que a empresa pode optar pelo recolhimento de uma ou outra (a partir de dezembro de 2015). Para esse último período foi calculado o quanto a empresa desembolsou contribuindo pela CPRB e quanto iria desembolsar se voltasse a recolher a CPP, uma avaliação relevante com vistas a obter uma economia tributária. Por meio de estudos prévios, realizados por Eckert, Mecca, Biasio e Silveira (2013), Oliveira, Petri, Casagrande e Rosa (2014) e Echevarrieta, Magalhães, Casagrande e Rosa (2015), respectivamente em uma metalúrgica fabricante de autopeças, em indústrias moveleiras e em um hotel, os autores constataram que a substituição da contribuição previdenciária patronal pela contribuição previdenciária sobre a receita bruta de fato representou uma redução na carga tributária das empresas analisadas.

\section{REFERENCIAL TEÓRICO}

\subsection{Encargos previdenciários sobre a folha de pagamentos e sobre a receita}

Segundo Martins (2009, p. 24), gastos referem-se à "compra de um produto ou serviço qualquer, que gera sacrifício financeiro para a entidade (desembolso), sacrifício esse representado por entrega ou promessa de entrega de ativos (normalmente dinheiro)". Dentre os diversos gastos incorridos pelas organizações estão aqueles relativos à mão de obra, que representam um percentual alto do faturamento para muitas empresas, especialmente para aquelas que se concentram na prestação de serviços.

Nas empresas de tecnologia da informação, de acordo com Kimura, Pereira e Antunes (2012), os gastos com mão de obra representam grande participação no total dos gastos, pois esses serviços demandam uso intensivo de capital intelectual. Os gastos relativos à mão de obra compreendem os encargos trabalhistas e os encargos sociais. Os valores pagos diretamente ao trabalhador, como salário, férias, adicional de férias, $13^{\circ}$ salário, repouso semanal remunerado, entre outros, são os encargos trabalhistas. Os recolhimentos feitos pelo empregador em benefício do empregado são chamados de encargos sociais. Consideram-se encargos sociais o Fundo de Garantia por Tempo de Serviço (FGTS), estabelecido pelo art. 15 da Lei n. 8.036/90, a Contribuição Previdenciária Patronal e o Seguro Acidente de Trabalho (SAT) (incisos I e II do art. 22 da Lei n. 8.212/91) e as contribuições a outras entidades e fundos, nestas incluídos o salário-educação e as contribuições ao INCRA, SENAI, SESI, SENAC, SESC, SEBRAE, DPC, FUNDO AEROVIÁRIO, SENAR, SEST, SENAT, SESCOOP, conforme estabelecido no Anexo I da Instrução Normativa n. 971/2009. A título de CPP os empregadores devem recolher $20 \%$ sobre os proventos pagos aos empregados. Relativamente ao SAT a legislação definiu que os empregadores recolhessem de $1 \%$ a 3\%, de acordo com o grau de risco de sua atividade. Para outras entidades e fundos, denominados terceiros, 5,8\%. Em relação ao FGTS a ser depositado para o empregado, a empresa recolhe 8\%.

De acordo com Martins (2009, p. 135), no Brasil os encargos sociais "são totalmente dependentes do pagamento feito, tornando-os um custo variável com relação a própria mão de obra e diretamente proporcionais a ela", enquanto que, segundo o autor, em outros países esses encargos assumem um caráter de custo fixo, por serem mais em função do número de pessoas do que do valor pago. De tal modo, considerando a magnitude desses gastos, bem como a sua variação em função dos valores despendidos com mão de obra, a mensuração adequada é fundamental para que a empresa obtenha um controle efetivo sobre os custos relativos a cada colaborador. Além disso, a mensuração e controle destes gastos tornam-se fundamentais para os setores econômicos que obtém mais intensivamente gastos com mão de obra, tais como os setores de serviços.

A Contribuição Previdenciária recolhida pelas empresas se destina ao financiamento da Seguridade Social e, segundo a Constituição Federal de 1988, poderá incidir sobre o valor da folha de pagamentos, da receita ou faturamento ou do lucro. 
Art. 195. A seguridade social será financiada por toda a sociedade, de forma direta e indireta, nos termos da lei, mediante recursos provenientes dos orçamentos da União, dos Estados, do Distrito Federal e dos Municípios, e das seguintes contribuições sociais:

I - do empregador, da empresa e da entidade a ela equiparada na forma da lei, incidentes sobre:

a) a folha de salários e demais rendimentos do trabalho pagos ou creditados, a qualquer título, à pessoa física que lhe preste serviço, mesmo sem vínculo empregatício;

b) a receita ou o faturamento;

c) o lucro;

[...]

$\S 12$. A lei definirá os setores de atividade econômica para os quais as contribuições incidentes na forma dos incisos I, b; e IV do caput, serão não-cumulativas.

$\S 13$. Aplica-se o disposto no $\S 12$ inclusive na hipótese de substituição gradual, total ou parcial, da contribuição incidente na forma do inciso I, a, pela incidente sobre a receita ou o faturamento (Constituição Federal de 1988, 1988).

A Contribuição Previdenciária a cargo das empresas está prevista no art. 22 da Lei n. 8.212/1991, que, entre outras providências, institui o Plano de Custeio da Seguridade Social. Os empregadores devem recolher, a título de contribuição previdenciária patronal, $20 \%$ sobre o total das remunerações pagas aos seus empregados, trabalhadores avulsos e autônomos que Ihes prestem serviços. De acordo com Ansiliero et al. (2010) e Kertzman (2012), o aumento de alíquota patronal das últimas décadas - que na origem da previdência era de apenas 3\% (Lei Eloy Chaves de 1923) e passou para os atuais $20 \%$, repercutiu mais fortemente em empresas e setores intensivos em mão de obra, desestimulando a geração ou a formalização de vínculos empregatícios. Assim, segundo Ansiliero et al. (2010, p. 10), "a substituição (total ou parcial) da alíquota patronal de $20 \%$ pela contribuição sobre a receita ou faturamento produziria certo alívio para firmas e setores de mão de obra intensivos" (...). Nesse sentido, Silva, Paes e Ospina (2014, p. 518) sugerem que essa substituição deve "ser feita em setores da economia considerados intensivos em trabalho".

Nesse contexto, em 2011, por meio da Medida Provisória n. 540 (posteriormente convertida na Lei n. 12.546 de 14 de dezembro de 2011), foi instituída a CPRB. Essa "nova" contribuição, popularmente denominada desoneração da folha de pagamentos, substituiu o recolhimento da CPP por uma nova contribuição previdenciária, cuja alíquota e base de cálculo são diferentes. Essa, determinada pela legislação, deve incidir sobre o faturamento (receita bruta) das empresas. Ferrari, Kremer e Silva (2014, p. 5) destacam que a desoneração da folha de pagamentos se constitui de duas medidas complementares:

Em primeiro lugar, o governo eliminou a atual contribuição previdenciária sobre a folha e adotou um novo modelo sobre a receita bruta das empresas (descontadas as receitas de exportação), em consonância com o disposto nas diretrizes da Constituição Federal. $\mathrm{E}$, em segundo lugar, essa mudança de base da contribuição também contempla uma redução da carga tributária dos setores beneficiados, porque a alíquota sobre a receita bruta foi fixada em um patamar inferior àquela alíquota - a chamada alíquota neutra.

Kertzman (2012, p. 168), por outro lado, afirma que a desoneração da folha de pagamentos não representa necessariamente redução dos custos tributários totais. De acordo com o autor, o que se pretende é "encontrar uma fonte de financiamento menos agressiva à sociedade, sem perda de recursos destinados à previdência social".

Já Silva et al. (2014, p. 518), ao analisarem os efeitos macroeconômicos da substituição da contribuição patronal pelo faturamento, afirmaram que "ao se substituir a alíquota patronal para o faturamento aos níveis de $1 \%$ ou $2 \%$, os grandes efeitos se dão em virtude da redução da carga tributária, mas sem impacto importante na diminuição das distorções do sistema tributário brasileiro".

Segundo Kertzman (2012), a substituição da CPP pela CPRB é um reflexo do agravamento do risco social do desemprego involuntário. Para Cavalcanti (2008, p. 258) um 
dos objetivos da substituição da tributação sobre a folha pelo faturamento "é estimular o aumento das relações formais de trabalho". Nessa seara, Silva et al. (2014, p. 544) constataram que "as firmas intensivas em trabalho apresentam um comportamento crescente na demanda laboral, mas que desacelera na medida em que a alíquota sobre o faturamento do setor aumenta".

Quando criada, a medida restringia-se apenas aos setores de call centers, Tecnologia da Informação (TI), Tecnologia da Informação e Comunicação (TIC), confecção, couros e calçados. Posteriormente foi ampliada para 56 setores da economia. A partir da sua instituição, as empresas elencadas pela legislação passaram a ser obrigadas a substituir o recolhimento da CPP pelo da CPRB. Após a promulgação da Lei n. 12.546/2011, as empresas listadas deixariam de contribuir com $20 \%$ sobre o total da folha de pagamento, devida durante o mês, aos segurados empregados e trabalhadores avulsos e aos segurados contribuintes individuais, que lhes prestassem serviços, conforme previsto no inciso I e III, do art. 22 da Lei n. 8.212 de 24 de julho de 1991. Passariam a apurar a contribuição previdenciária com a aplicação da alíquota, definida pela legislação, sobre a receita bruta, excluídas as vendas canceladas, os descontos incondicionais concedidos, as receitas decorrentes de exportação, o Imposto sobre Produtos Industrializados - IPI (se incluído na receita bruta) e o Imposto sobre Operações relativas à Circulação de Mercadorias e sobre Prestações de Serviços de Transporte Interestadual e Intermunicipal e de Comunicação - ICMS, quando cobrado pelo vendedor dos bens ou prestador dos serviços na condição de substituto tributário.

Para as empresas de tecnologia da informação a alíquota, estabelecida inicialmente pela legislação, era de $2,5 \%$. A partir de $1^{\circ}$ de agosto de 2012, após algumas alterações ocorridas na legislação, a alíquota passou a ser de $2 \%$. A mais recente alteração, que passou vigorar a partir de 01/12/2015, majorou as alíquotas, passando para 4,5\% a incidência sobre a receita bruta (art. $7^{\circ}$ da Lei n. 12.546 de 2011 e alterações posteriores).

Além da majoração da alíquota, uma alteração recente trazida pela Lei n. 13.161/2015, permitiu a opção pelo recolhimento da CPP. A partir de $1^{\circ}$ de dezembro de 2015 as empresas incluídas na desoneração da folha de pagamentos podem optar por recolher a CPP ou a CPRB. Diferentemente da CPP, que deve ser recolhida por meio da Guia da Previdência Social (GPS), a CPRB deve ser recolhida através do Documento de Arrecadação de Receitas Federais (DARF), ambas até o dia 20 do mês subsequente ao da competência em que se tornarem devidas.

De acordo com as novas regras, a opção pela tributação substitutiva será manifestada por meio do pagamento da contribuição incidente sobre a receita bruta relativa a janeiro de cada ano, ou à primeira competência subsequente para a qual haja receita bruta apurada, e será irretratável para todo o ano calendário. Segundo a nova Lei, excepcionalmente para o ano de 2015, a opção deve ser manifestada mediante o pagamento da contribuição incidente sobre a receita bruta relativa ao mês de novembro (art. $9^{\circ}$, $\$ 13$ e $\$ 14$ da Lei $n$. 12.546/2011). Essa redação resultou em entendimentos divergentes dentre os contribuintes, o que foi esclarecido com a publicação da Instrução Normativa n. 1.597 de 01 de dezembro de 2015, que dispôs que o recolhimento com a alíquota majorada somente valerá a partir da competência de dezembro, cujo recolhimento da CPRB se dará em janeiro de 2016. Do mesmo modo, para os contribuintes que, em dezembro de 2015, optarem pelo retorno à tributação pela CPP. Por meio da Figura 1 é apresentada uma síntese das principais diferenças entre os dois tipos de recolhimentos.

\begin{tabular}{|l|l|}
\hline \multicolumn{1}{|c|}{ CPP } & \multicolumn{1}{|c|}{ CPRB } \\
\hline Aplicável a todos os setores & Aplicável a setores específicos \\
\hline $\begin{array}{l}\text { Recolhimento sobre os proventos pagos aos } \\
\text { empregados }\end{array}$ & $\begin{array}{l}\text { Recolhimento sobre o faturamento ajustado (receita } \\
\text { bruta ajustada) das empresas }\end{array}$ \\
\hline $\begin{array}{l}\text { Recolhida por meio da Guia da previdência Social } \\
\text { (GPS) }\end{array}$ & $\begin{array}{l}\text { Recolhida por meio do Documento de Arrecadação de } \\
\text { Receitas Federais (DARF) }\end{array}$ \\
\hline $\begin{array}{l}\text { Em termos de montante final, tende a ser maior } \\
\text { quando a utilização de mão de obra é alta e o } \\
\text { faturamento é baixo }\end{array}$ & $\begin{array}{l}\text { Em termos de montante final, tende a ser maior em } \\
\text { atividades em que o faturamento é alto e a utilização de } \\
\text { mão de obra é baixa }\end{array}$ \\
\hline
\end{tabular}

Figura 1. Síntese das principais diferenças entre os tipos de recolhimento

Fonte: Dados da pesquisa (2016). 
De acordo com as diferenças apresentadas na Figura 1, nos setores da economia em que a CPRB é aplicável, os impactos nos gastos das empresas com encargos trabalhistas pode ser representativo. Nesse sentido, devem os gestores considerar o faturamento ajustado e os proventos pagos aos empregados para fins de simulação. Com o intuito de ilustrar essas análises em uma empresa de tecnologia da informação, recorreu-se a estudos anteriores, a fim de explorar os procedimentos empregados e os resultados por eles alcançados.

\subsection{Estudos anteriores}

Fez-se um levantamento de estudos anteriores sobre o tema, com o intento de identificar os procedimentos utilizados e os resultados obtidos. Para tanto, são apresentados por meio da Figura 2 o objetivo, os procedimentos utilizados e os principais resultados.

\begin{tabular}{|c|c|c|c|}
\hline Autores & Objetivos & Procedimentos & Resultados \\
\hline $\begin{array}{l}\text { Eckert et al. } \\
(2013)\end{array}$ & $\begin{array}{l}\text { Analisar os impactos da } \\
\text { desoneração da folha de } \\
\text { pagamento em uma } \\
\text { empresa metalúrgica do } \\
\text { setor de autopeças }\end{array}$ & $\begin{array}{l}\text { Pesquisa exploratória, por } \\
\text { meio de um estudo de } \\
\text { caso, com abordagem } \\
\text { qualitativa }\end{array}$ & $\begin{array}{l}\text { Significativa redução no valor dos } \\
\text { encargos trabalhistas a partir da } \\
\text { desoneração da folha de } \\
\text { pagamentos }\end{array}$ \\
\hline $\begin{array}{l}\text { Oliveira et } \\
\text { al.(2014) }\end{array}$ & $\begin{array}{l}\text { Verificar o impacto da } \\
\text { mudança na forma de } \\
\text { cálculo da contribuição } \\
\text { previdenciária em } \\
\text { empresas do setor } \\
\text { moveleiro }\end{array}$ & $\begin{array}{l}\text { Pesquisa descritiva em } \\
\text { estudo de caso, com } \\
\text { abordagem quantitativa }\end{array}$ & $\begin{array}{l}\text { Independente da divergência, tanto } \\
\text { em números de faturamento quanto } \\
\text { em relação ao número de } \\
\text { empregados, nas duas empresas } \\
\text { analisadas, ambas foram } \\
\text { desoneradas em sua contribuição, } \\
\text { chegando a ultrapassar } 70 \% \text { de } \\
\text { economia nos dois anos analisados }\end{array}$ \\
\hline $\begin{array}{l}\text { Bertini \& } \\
\text { Wunsch } \\
(2014)\end{array}$ & $\begin{array}{l}\text { Evidenciar o impacto da } \\
\text { desoneração da folha de } \\
\text { pagamento em indústrias } \\
\text { calçadistas }\end{array}$ & $\begin{array}{l}\text { Pesquisa de levantamento } \\
\text { com abordagem qualitativa } \\
\text { e quantitativa }\end{array}$ & $\begin{array}{l}\text { Redução dos custos e impacto } \\
\text { financeiro positivo nas empresas } \\
\text { analisadas }\end{array}$ \\
\hline $\begin{array}{l}\text { Echevarrieta } \\
\text { et al. (2015) }\end{array}$ & $\begin{array}{l}\text { Verificar a influência da } \\
\text { contribuição previdenciária } \\
\text { antes e depois da } \\
\text { desoneração da folha de } \\
\text { pagamento em um Hotel } \\
\text { da Grande Florianópolis }\end{array}$ & $\begin{array}{l}\text { Estudo descritivo, com } \\
\text { estudo de caso e } \\
\text { abordagem qualitativa }\end{array}$ & $\begin{array}{l}\text { Redução de custos laborais a partir } \\
\text { da redução da contribuição } \\
\text { previdenciária, apontando uma } \\
\text { desoneração da folha de } \\
\text { pagamentos }\end{array}$ \\
\hline $\begin{array}{l}\text { Ludwig et al. } \\
(2016)\end{array}$ & $\begin{array}{l}\text { Verificar se houve redução } \\
\text { dos custos em duas } \\
\text { empresas analisadas do } \\
\text { segmento da construção } \\
\text { civil }\end{array}$ & $\begin{array}{l}\text { Estudo de caso com } \\
\text { abordagem quantitativa }\end{array}$ & $\begin{array}{l}\text { A empresa que utiliza mão de obra } \\
\text { própria obteve benefícios com a } \\
\text { alteração da legislação, entre eles a } \\
\text { redução do valor pago à } \\
\text { previdência, enquanto que na } \\
\text { empresa que detém mão de obra } \\
\text { terceirizada os benefícios não foram } \\
\text { verificados, nem de modo indireto }\end{array}$ \\
\hline
\end{tabular}

Figura 2. Objetivos, procedimentos e resultados de estudos anteriores

Fonte: Elaborado a partir dos estudos identificados (2016).

Os estudos identificados na Figura 2, embora tenham tratado de objetos empíricos diferentes em termos de porte e segmento econômico, apresentam semelhanças nos objetivos, procedimentos e resultados alcançados. A análise do impacto da desoneração da folha de pagamentos nos encargos trabalhistas incorridos é comum nos objetivos dos estudos. Com exceção de Bertini e Wunsch (2014), as demais pesquisas utilizaram estudo de caso enquanto procedimento de pesquisa. Quanto aos resultados, também ficou evidente em todos os estudos os aspectos positivos decorrentes da desoneração da folha de pagamentos, dentre eles, a redução dos encargos trabalhistas incorridos.

\section{PROCEDIMENTOS METODOLÓGICOS}

Em relação ao seu objetivo, que é comparar os gastos da empresa com contribuição previdenciária entre 2011 e 2016, esta pesquisa pode ser classificada como descritiva, que, 
conforme Triviños (1987), exige do pesquisador uma delimitação precisa de técnicas, métodos, modelos e teorias que orientarão a coleta e a análise dos dados, cujo objetivo é conferir validade científica ao trabalho.

Quanto aos procedimentos técnicos, classifica-se como em estudo de caso, que, de acordo com Yin (2001, p. 32), "é uma investigação empírica que investiga um fenômeno contemporâneo dentro de seu contexto da vida real, especialmente quando os limites entre o fenômeno e o contexto não estão claramente definidos". Para Gil (2008, p. 57), "o estudo de caso é caracterizado pelo estudo profundo e exaustivo de um ou de poucos objetos, de maneira a permitir o seu conhecimento amplo e detalhado".

A escolha do caso, uma empresa de Tecnologia da Informação, está pautada em três principais razões: a primeira delas diz respeito ao fato de que a empresa pertence a um setor contemplado pela desoneração da folha de pagamentos, portanto, passível de estudo; como segunda razão, optou-se por um caso cujo tipo de empresa ainda não tivesse sido objeto de investigação de muitos estudos, como pode ser observado na Figura 2; a terceira razão, relacionada à segunda, refere-se a um caso com intenso uso de mão de obra, o que torna interessante comparar o recolhimento sobre o faturamento e sobre os proventos.

Quanto à abordagem do problema, a pesquisa está classificada como quali-quantitativa, que, conforme Koche (2006), se preocupa com a compreensão e a interpretação do fenômeno. Tem como principal objetivo compreender, explorar e especificar o cenário existente.

Esta pesquisa foi realizada com base nos dados do faturamento (receita bruta) e da folha de pagamentos relativos ao período de janeiro de 2011 a dezembro de 2016. Para coleta dos dados foram utilizados relatórios de folha de pagamentos disponibilizados pela empresa e a Demonstração de Resultados do Exercício, disponibilizada pelo Contador, ambos emitidos com periodicidade mensal. Além disso, também foram utilizadas entrevistas semiestruturadas com gestores da empresa e também com o Contador para sanar dúvidas sobre os relatórios recebidos.

Os dados disponibilizados por meio de relatórios e de entrevistas semiestruturadas foram analisados e tratados pela técnica da análise descritiva, operacionalizada a partir de planilhas eletrônicas para apuração dos gastos com as contribuições previdenciárias: a) patronal (de janeiro a novembro de 2011); e b) sobre a receita bruta (de dezembro de 2011 até 2016). Considerando que a partir de dezembro de 2015 a empresas pôde optar pelo recolhimento de uma ou de outra contribuição previdenciária, foi feita uma análise para identificar qual seria menos oneroso para a empresa a partir daquele mês.

\section{RESULTADOS}

\subsection{Apresentação da empresa}

A empresa objeto de estudo é uma sociedade por ações de capital fechado, situada em Florianópolis, que presta serviços para clientes localizados em várias regiões do Brasil e iniciou suas atividades em 2004. Segundo a classificação proposta pelo Banco Nacional de Desenvolvimento Econômico e Social (BNDES), por meio das Circulares 11/2010 e 34/2011, no que diz respeito ao seu faturamento, é uma empresa de pequeno porte. Atualmente é composta por uma equipe formada por 61 colaboradores e tributa o IRPJ pelo Lucro Real.

Desde a instituição da contribuição previdenciária substitutiva, a empresa tem obtido um faturamento (receita bruta) crescente. A receita bruta da empresa, constante na Tabela 1, é composta pelos serviços prestados nos anos de 2011, 2012, 2013, 2014, 2015 e 2016. Não houveram vendas canceladas, descontos incondicionais concedidos, receitas decorrentes de exportações diretas, Imposto sobre Produtos Industrializados (IPI) e o Imposto sobre Operações relativas à Circulação de Mercadorias e sobre Prestações de Serviços de Transporte Interestadual e Intermunicipal e de Comunicação decorrente de substituição tributária (ICMS ST). 
Tabela 1

Receita bruta realizada - 2011 a 2016

\begin{tabular}{c|c|c|c|c|c|c}
\hline Ano & 2011 & 2012 & 2013 & 2014 & 2015 & 2016 \\
\hline $\begin{array}{l}\text { Receita } \\
\text { bruta }\end{array}$ & $2.355 .596,44$ & $3.365 .296,32$ & $5.529 .615,28$ & $5.842 .143,20$ & $7.425 .649,50$ & $9.879 .373,40$ \\
\hline
\end{tabular}

Nota. Fonte: Dados da pesquisa (2016).

Nesse mesmo período, a empresa obteve gastos com folha de pagamentos, relativos a salários, pró-labore, $13^{\circ}$ salário, férias, FGTS, SAT, Terceiros, vale refeição, vale transporte, planos de saúde e plano odontológico. Os gastos com remuneração da folha de pagamentos (salários, pró-labore, $13^{\circ}$ salário e férias) que constituem a base para cálculo da Contribuição Previdenciária Patronal, relativos ao período de 2011 a 2016, são demonstrados na Tabela 2.

Tabela 2

Proventos de 2011 a 2016

\begin{tabular}{c|c|c|c|c|c|c}
\hline Ano & 2011 & 2012 & 2013 & 2014 & 2015 & 2016 \\
\hline Proventos & $987.649,81$ & $1.307 .116,09$ & $1.833 .493,00$ & $2.380 .139,63$ & $2.864 .422,40$ & $3.444 .398,50$ \\
\hline
\end{tabular}

Nota. Fonte: Dados da pesquisa (2016).

Em 2011, ano em que foi instituída a desoneração da folha de pagamentos, a empresa tinha uma equipe formada por 24 profissionais. Essa equipe se manteve até 2013, passando para 38 em 2014, 50 em 2015 e 61 em 2016. Com essas informações é possível demonstrar, por meio da Tabela 3, a variação de crescimento da receita bruta, proventos e número de funcionários no período que vai de 2011 a 2016. Houve um aumento de faturamento de $43 \%$ em 2012, em relação a 2011. O mesmo ocorreu em 2013, quando o aumento foi de $64 \%$, comparado ao obtido pela empresa em 2012. Já em 2014 o crescimento das receitas foi menor (6\%), voltando a crescer com maior intensidade em 2015 (27\%) e 2016 (33\%).

Tabela 3

Crescimento anual das variáveis receita bruta, proventos e número de funcionários

\begin{tabular}{l|c|c|c|c|c|c}
\hline \multicolumn{1}{c|}{ Ano } & 2011 & 2012 & 2013 & 2014 & 2015 & 2016 \\
\hline $\begin{array}{l}\text { Receita } \\
\text { bruta (R\$) }\end{array}$ & $2.355 .596,44$ & $3.365 .296,32$ & $5.529 .615,28$ & $5.842 .143,20$ & $7.425 .649,50$ & $9.879 .373,40$ \\
\hline $\begin{array}{l}\text { Crescimento } \\
\text { anual RB } \\
(\%)\end{array}$ & 0,00 & $43 \%$ & $64 \%$ & $6 \%$ & $27 \%$ & $33 \%$ \\
\hline $\begin{array}{l}\text { Proventos } \\
(\mathrm{R} \$)\end{array}$ & $987.649,81$ & $1.307 .116,09$ & $1.833 .493,00$ & $2.380 .139,63$ & $2.864 .422,40$ & $3.444 .398,50$ \\
\hline $\begin{array}{l}\text { Crescimento } \\
\text { anual }\end{array}$ & 0,00 & $32 \%$ & $40 \%$ & $30 \%$ & $20 \%$ & $20 \%$ \\
$\begin{array}{l}\text { Proventos } \\
(\%)\end{array}$ & 24 & 24 & 24 & 38 & 50 & 61 \\
\hline $\begin{array}{l}N^{\circ} \text { de } \\
\text { funcionários }\end{array}$ & 0,00 & $0 \%$ & $0 \%$ & $58 \%$ & $32 \%$ & $22 \%$ \\
\hline $\begin{array}{l}\text { Crescimento } \\
\text { anual } n^{\circ} \\
\text { funcionários } \\
(\%)\end{array}$ & & & & & \\
\hline
\end{tabular}

Nota. Fonte: Dados da pesquisa (2016).

Os gastos com proventos acompanharam a expansão do faturamento da empresa, porém de forma mais tímida. Atingiram o maior percentual no ano de 2013, quando aumentaram $40 \%$ em relação ao ano anterior. Em 2015, ainda em crescimento, os gastos com proventos foram $20 \%$ superiores aos do ano anterior. Já no que diz respeito ao número de funcionários, a empresa manteve a equipe de 2011 até 2013. Aumentou o seu quadro em $58 \%$ no ano de 2014 (em relação a 2013) e em 32\% no ano de 2015 (em relação a 2014).

Em 2011, 2012 e 2013 houve crescimento tanto de receita bruta quanto de dispêndios com salários, pró-labore, $13^{\circ}$ salário e férias, enquanto que o número de funcionários se manteve inalterado. Já em 2014, o número de funcionários aumentou mais que $50 \%$ e as receitas cresceram em percentual inferior a $10 \%$, enquanto os gastos com proventos tiveram 
um crescimento de $30 \%$. A partir destas observações, passa-se a análise dos dispêndios obtidos pela empresa com a CPP e com a CPRB no período 2011 a 2016.

\subsection{Análise dos resultados}

Para melhor demonstrar os resultados da pesquisa, primeiramente são analisadas as variações ocorridas nos desembolsos com contribuição previdenciária devida no período que compreende janeiro de 2011 a novembro de 2015. Após é apresentada a contribuição previdenciária devida a partir de dezembro de 2015, considerando a possibilidade de a empresa optar pelo recolhimento da CPP ou da CPRB. Nesse caso, são comparadas as duas opções para identificar a mais econômica para a empresa. Por fim, é apresentado quanto a empresa desembolsou com contribuição previdenciária no período que compreende 2011 a 2016.

\subsubsection{Contribuição previdenciária devida no período que compreende janeiro de 2011 a novembro de 2015}

Conforme já evidenciado, até 30 de novembro de 2011, a empresa estava obrigada ao recolhimento da CPP, ou seja, até essa data deveria recolher $20 \%$ sobre os proventos dos funcionários e diretores. Em 2011 foram recolhidos, a título de CPP, R\$ 175.938,20, conforme demonstrado na Tabela 4.

Tabela 4

Contribuição previdenciária devida de 2011 a 30/11/2015

\begin{tabular}{l|l|l|l|l|l}
\hline \multicolumn{1}{c|}{ Ano } & \multicolumn{1}{c|}{2011} & 2012 & \multicolumn{1}{c|}{2013} & \multicolumn{1}{c}{2014} & \multicolumn{1}{c}{2015} \\
\hline CPP & $175.938,20$ & - & - & - & - \\
\hline CPRB & $8.614,83$ & $75.903,22$ & $110.592,31$ & $116.842,86$ & $136.136,91$ \\
\hline Total Anual & $184.553,03$ & $75.903,22$ & $110.592,31$ & $116.842,86$ & $136.136,91$ \\
\hline Nota. Fonte: Dados da pesquisa (2016)
\end{tabular}

A partir de dezembro de 2011, a empresa esteve obrigada ao recolhimento da contribuição previdenciária à alíquota de $2,5 \%$ sobre a receita bruta. A Tabela 4 demonstra os valores desembolsados pela empresa a partir desse período. Para o período que se iniciou em agosto de 2012 até 30 de novembro de 2015, a legislação foi alterada e o recolhimento da CPRB passou a uma alíquota de $2 \%$. Esse fato fez diminuir novamente o valor da contribuição previdenciária a ser recolhida pela empresa. Com a desoneração da folha de pagamentos a empresa passou a desembolsar menos com contribuição previdenciária. Em relação aos gastos com este tributo obtidos em 2011, em 2012 a empresa economizou quase 60\%. Exclusivamente em função do aumento de receita, a partir de dezembro de 2011, houve um reflexo nos desembolsos com contribuição previdenciária, que aumentaram gradativamente no decorrer dos anos seguintes. Em 2015 os gastos com contribuição previdenciária ainda não atingem o patamar de gastos que a empresa obteve em 2011, quando na maior parte do ano contribuiu com CPP.

É importante destacar que em 2015 não foi considerada a contribuição previdenciária devida ao mês de dezembro, pois a partir desse mês a CPRB foi calculada considerando a majoração da alíquota para $4,5 \%$. Por incidirem diretamente sobre a receita bruta, os gastos com contribuição previdenciária do período de $1^{\circ}$ de dezembro de 2011 até 30 de novembro de 2015 foram diretamente proporcionais, ou seja, de 2,5\% sobre a receita bruta de 01/12/2011 até $31 / 07 / 2012$ e de $2 \%$ de 01/08/2012 até 30/11/2015.

\subsubsection{Contribuição previdenciária devida a partir de dezembro de 2015}

A partir de $1^{\circ}$ de dezembro de 2015 a empresa pôde optar por continuar recolhendo a CPRB ou voltar a recolher a CPP. Todavia, a partir dessa data a alíquota que incidiu sobre a receita bruta foi de $4,5 \%$. Considerando esse fato e os dados relativos à receita bruta e aos proventos, elaborou-se a Tabela 5 que discrimina os desembolsos que a empresa teve com a CPRB e aqueles que teria caso tivesse feito a opção pela CPP. Ressalva-se que o comparativo 
entre os métodos de recolhimento foi feito apenas para o período apresentado na Tabela 5, pois nos períodos anteriores não houve a possibilidade de a empresa optar por um ou por outro tipo de recolhimento.

Tabela 5

Recolhimento de contribuição previdenciária pela CPP e pela CPRB

\begin{tabular}{c|c|c}
\hline Contribuição Previdenciária & Dezembro de 2015 & 2016 \\
\hline CPP & $47.740,37$ & $688.879,70$ \\
\hline CPRB & $27.846,19$ & $444.571,80$ \\
\hline
\end{tabular}

Nota. Fonte: Dados da pesquisa (2016).

Os gastos com a CPRB são inferiores aos gastos com a CPP, ou seja, tanto para as contribuições devidas, relativas a 2015 e aquelas relativas a 2016, a opção por continuar recolhendo a CPRB fez com que a empresa desembolsasse menos com contribuição previdenciária. Assim, a Tabela 5 demonstra que foi mais econômico para a empresa continuar recolhendo a contribuição à previdência com base na receita bruta.

Considerando que a alíquota incidente sobre a receita bruta é de $4,5 \%$ e que a alíquota incidente sobre os proventos da folha de pagamentos é de $20 \%$, é possível afirmar que se o valor da folha de pagamentos for inferior a $22,5 \%$ do faturamento da empresa, é mais vantajoso recolher a CPP. Consequentemente, se os gastos com a folha de pagamentos ultrapassarem $22,5 \%$ do faturamento é mais vantajoso recolher a CPRB. A empresa, objeto deste estudo, tem um histórico de gastos com proventos da folha de pagamentos superior a $30 \%$ dos valores correspondentes à receita bruta, o que demonstra que a melhor opção é recolher a CPRB.

\subsubsection{Evolução dos recolhimentos de contribuição previdenciária devida de 2011 a 2016}

Com a instituição da desoneração da folha de pagamentos, a partir de 01/12/2011, a empresa teve uma queda no recolhimento de contribuição previdenciária, corroborando o que afirmaram os autores Ansiliero et al. (2010), Ferrari et al. (2014) e Silva et al. (2014), ao defenderem que a mudança da base de cálculo da contribuição previdenciária resultaria em uma redução da carga tributária dos setores beneficiados. Em relação ao que recolhia em 2011, a empresa obteve economia nos anos subsequentes, até 2015. No ano de 2012 os valores de contribuição previdenciária pagos pela empresa foram menores que $50 \%$, quando comparados ao que fora pago em 2011. Nos anos de 2013 e 2014, os pagamentos atingiram uma média de $60 \%$ em relação ao que a empresa pagou em 2011.

Este estudo demonstrou, portanto, que a substituição da CPP pela CPRB representou uma redução na carga tributária da empresa analisada, assim como os resultados alcançados por Eckert et al. (2013), Oliveira et al.(2014), Bertini e Wunsch (2014), Echevarrieta et al. (2015), Ludwig, Borgert e Kremer (2016), que constataram a redução no recolhimento da contribuição previdenciária em diversos outros setores confirmando aspectos positivos decorrentes da desoneração da folha de pagamentos.

Em 2016, devido ao aumento da alíquota da CPRB, de $2 \%$ para 4,5\% (125\%), a empresa aumentou consideravelmente os gastos com contribuição previdenciária. É importante destacar que, embora essa alíquota tenha aumentado, a empresa de fato teve uma desoneração nos gastos com folha de pagamentos. Essa desoneração iniciou no final de 2011 e continua sendo relevante para a empresa, de modo que em 2016 foi mais interessante continuar recolhendo a CPRB.

\section{CONCLUSÃO}

Os crescentes gastos das empresas, aliado à concessão de benefícios, no que diz respeito a determinados tributos, evidencia a necessidade de planejamento e de construção de projeções, a fim de proporcionar uma economia às organizações. Nesse sentido, o objetivo desta pesquisa consistiu em investigar o impacto da "desoneração da folha de pagamentos" sobre os gastos com encargos trabalhistas incorridos por uma empresa de tecnologia da informação localizada em Florianópolis. 
Os achados do estudo evidenciam que desde a sua instituição, a desoneração da folha de pagamentos foi benéfica para a empresa, representando uma economia significativa no que diz respeito aos gastos com encargos trabalhistas, mais especificamente, com contribuição previdenciária. Concluiu-se que, no que diz respeito aos gastos com contribuição previdenciária, a empresa, de fato, foi desonerada. A partir de dezembro de 2011 a empresa passou a recolher a CPRB, o que fez com que seus recolhimentos a título de contribuição previdenciária diminuíssem inicialmente em mais de $50 \%$.

Somente em 2015, quando atingiu um faturamento quase 3 vezes maior do que em 2011, a empresa recolheu a título de contribuição previdenciária valores aproximados aos que dispendia naquela época. Para a empresa, a partir de dezembro de 2015, os gastos com contribuição previdenciária aumentaram, devido à majoração de $125 \%$ na alíquota da CPRB. Foi identificado, ainda, que, somente se o valor da folha de pagamentos for inferior a $22,5 \%$ do faturamento da empresa, será mais vantajoso recolher a contribuição previdenciária patronal. Pois, caso os gastos com folha de pagamentos sejam superiores a $22,5 \%$ do faturamento é mais vantajoso recolher a contribuição previdenciária sobre a receita bruta.

Deve se atentar ao fato de que atualmente a empresa despende um pouco mais que $30 \%$ do faturamento com folha de pagamentos. Portanto, desde a implementação da desoneração da folha de pagamentos a melhor opção foi e continua sendo recolher a CPRB. Como decorrência natural dos procedimentos metodológicos adotados, os resultados alcançados dizem respeito ao caso estudado, que se insere em um setor cujo custo de mão de obra é a maior parcela do custo para gerar receita. Portanto, em setores com menor intensidade do uso de mão de obra isso pode não se repetir, o que sugere estudos futuros para verificar essa situação.

\section{REFERÊNCIAS}

Ansiliero, G., Leonardo, A. R., Paiva, L. H., Stivali, M., Barbosa, E. D., \& Silveira, F. G. (2010). A desoneração da folha de pagamentos e sua relação com a formalidade no mercado de trabalho. In Castro, J. A. de, Santos, C. H. M. dos, \& Ribeiro, J. A. C. (Org.). Tributação e equidade no Brasil: um registro da reflexão do IPEA no biênio 2008- 2009. Brasília: IPEA.

Banco Nacional de Desenvolvimento. Porte de empresa. Recuperado em 01 novembro, 2015, de http://www.bndes.gov.br/SiteBNDES/bndes/bndes_pt/Institucional/Apoio_Financeiro/p orte.html

Bertini, E. R., \& Wunsch, P. E. R. (2014). O impacto financeiro e contábil da desoneração da folha de pagamento em indústrias calçadistas do Vale do Paranhana. Revista Eletrônica do Curso de Ciências Contábeis, 3(4), 21-50.

Cavalcanti, T. V. (2008). Tributos sobre a folha ou sobre o faturamento? Efeitos quantitativos para o Brasil. Revista Brasileira de Economia, 62(3), 249-261.

Constituição Federal de 1988. (1988). Constituição da República Federativa do Brasil de 1988. Disponível em:<http://www.planalto.gov.br/ccivil_03/Constituicao/Constituicao.htm>. Acesso em: 10/11/ 2015.

Dallava. C. C. (2014). Impactos da desoneração da folha de pagamentos sobre o nível de emprego no mercado de trabalho brasileiro: um estudo de caso a partir dos dados da RAIS. Dissertação de mestrado, Fundação Getúlio Vargas, São Paulo, SP, Brasil.

Decreto n. 7.540 de 2 de agosto de 2011. (2011). Diário Oficial [da] República Federativa do Brasil. Brasília. Recuperado em 10 novembro, 2015, de http://www.planalto.gov.br/ccivil_03/_Ato2011-2014/2011/Decreto/D7540.htm

Eckert, A., Mecca, M. S., Biasio, R., \& Silveira, M. P. (2013). Impacto da desoneração da folha de pagamento: estudo de caso em uma metalúrgica fabricante de autopeças. $\begin{array}{lllll}\text { Recuperado em } \quad 30 & \text { dezembro, }\end{array}$ http://www.convibra.org/upload/paper/2013/34/2013_34_8207.pdf

Echevarrieta, A. C. C., Magalhães, R. A., Casagrande, M. D. H., \& Rosa, P. A. (2015). 
Desoneração da folha de pagamento: impactos fiscais e econômicos de um hotel em Florianópolis. Revista de Gestão e Tecnologia, 5(2), 27-39.

Ferrari, M. J., Kremer, A. W., \& Silva, M. C. (2014). Desoneração da folha de pagamento e comportamento dos custos das empresas de fios e tecidos do estado de Santa Catarina listadas na BM\&F BOVESPA. Anais do Congresso Brasileiro de Custos, Natal, RN, Brasil, 21.

Gil, A. C. (2008). Como elaborar projetos de pesquisa. São Paulo: Atlas.

Instrução Normativa n. 971, de 13 de novembro de 2009 (2009). Diário Oficial [da] República Federativa do Brasil. Brasília. Recuperado em 01 novembro, 2015, de http://www3.dataprev.gov.br/sislex/paginas/38/MF-RFB/2009/971.htm

Instrução Normativa n. 1.597, de 01 de dezembro de 2015. (2015). Diário Oficial [da] República Federativa do Brasil. Brasília. Recuperado em 05 dezembro, 2015, de http://normas.receita.fazenda.gov.br/sijut2consulta/link.action?visao=anotado\&idAto=699 71

Instrução Normativa n. 1.436, de 30 de dezembro de 2013. (2013). Diário Oficial [da] República Federativa do Brasil. Brasília. Recuperado em 05 dezembro, 2015, de http://normas.receita.fazenda.gov.br/sijut2consulta/link.action?idAto=48917\&visao=anota do

Kertzman, I. (2012). A desoneração da folha de pagamento. Dissertação de Mestrado, Universidade Federal da Bahia, Salvador, BA, Brasil.

Koche, J. C. (2006). Fundamentos de metodologia científica. Editora Vozes LTDA.

Kimura, H., Pereira L. C. J., \& Antunes, M. T. P. (2012). Análise simplificada de custos de Tecnologia de Informação. Contextus Revista Contemporânea de Economia e Gestão, 10(2), 61-82.

Lei n. 8.212, de 24 de julho de 1991.(1991). Diário Oficial [da] República Federativa do Brasil. Brasília. Recuperado em 01 novembro, 2015, de http://www.planalto.gov.br/ccivil_03/leis//8212cons.htm

Lei n. 8.036, de 11 de maio de 1990. (1990). Diário Oficial [da] República Federativa do Brasil. Brasília. Recuperado em 01 novembro, 2015, de http://www.planalto.gov.br/ccivil_03/LEIS/L8036consol.htm

Lei n. 12.546, de 14 de dezembro de 2011. (2011). Diário Oficial [da] República Federativa do Brasil. Brasília. Recuperado em 01 novembro, 2015, de http://www.planalto.gov.br/ccivil_03/_ato2011-2014/2011/lei/l12546.htm

Lei n. 12.715, de 17 de setembro de 2012. (2012). Diário Oficial [da] República Federativa do Brasil. Brasília. Recuperado em 01 novembro, 2015, de http://www.planalto.gov.br/ccivil_03/_ato2011-2014/2012/Lei/L12715.htm\#art55

Lei n. 13.161, de 31 de agosto de 2015. (2015). Diário Oficial [da] República Federativa do Brasil. Brasília. Recuperado em 01 novembro, 2015, de http://www.planalto.gov.br/ccivil_03/_Ato2015-2018/2015/Lei/L13161.htm\#art2

Ludwig, M. J., Borgert, A., \& Kremer, A. W. (2016). Desoneração da Folha de Pagamento e Comportamento dos Custos em Empresas de Construção Civil. Pensar Contábil, 18(66), 14-23.

Maher, M. (2001). Contabilidade de custos: criando valor para a administração. São Paulo: Atlas.

Martins, E. (2009). Contabilidade de custos. São Paulo: Atlas.

Medida Provisória n. 540 de 2 de agosto de 2011. (2011). Diário Oficial [da] República Federativa do Brasil. Brasília. Recuperado em 10 novembro, 2015, de http://www.planalto.gov.br/ccivil_03/_ato2011-2014/2011/mpv/540.htm 
Ministério da Fazenda. Cartilha da desoneração da folha. Recuperado em 05 novembro, 2015, de http://www1.fazenda.gov.br/portugues/documentos/2012/cartilhadesoneracao.pdf

Oliveira, A. M. B., Petri, S. M., Casagrande, M. D. H., \& Rosa, M. M. (2014). O impacto da mudança de base de cálculo e alíquota da contribuição previdenciária patronal em empresas do setor moveleiro. Revista da UNIFEBE, 1(14), 35-48.

Plano Brasil Maior. Plano Brasil Maior: Inovar para competir. Competir para crescer. (2011). Recuperado em 16 outubro, 2015, de http://www.brasilmaior.mdic.gov.br/wp-content/uploads/cartilha_brasilmaior.pdf.

Silva, W. B., Paes, N. L., \& Ospina, R. (2014). A substituição da contribuição patronal para o faturamento: efeitos macroeconômicos, sobre a progressividade e distribuição de renda no Brasil. Revista Brasileira de Economia, 68(4), 517-545.

Triviños, A. N. S. (1987). Introdução à pesquisa em ciências sociais. Rio de Janeiro: F. Alves.

Yin, R. K. (2001). Estudo de caso: planejamento e métodos. Porto Alegre: Bookman. 